\title{
Profound reduction of CD4+ lymphocytes without HIV infection: two cases from the horn of Africa
}

\author{
*Ollé-Goig JE , Ramírez J2 , Cervera C $\mathrm{C}^{3}$, Miró JM ${ }^{3}$
}

1. Catalan Association for the Control of Tuberculosis in the Third World (ACTMON), Barcelona, Spain. Formerly at Infectious Diseases Department, Hôpital Général Peltier, Djibouti. 2. Pathology Department, Hospital Clinic - IDIBAPS, University of Barcelona, Barcelona, Spain. 3. Infectious Diseases Service, Hospital Clinic - IDIBAPS. University of Barcelona, Barcelona (Spain).

\begin{abstract}
Idiopathic CD4+ lymphocytopenia is a disorder associated with low CD4+ T cell count and opportunistic infections resembling AIDS. Most cases are described in developed countries. We report two HIV-negative patients with idiopathic CD4+ lymphocytopenia and AIDS-defining events diagnosed in Djibouti. The first patient developed lesions of Kaposi's sarcoma and the second one presented with pulmonary tuberculosis. Both patients died with severe immunodepression. In poor resource-areas where HIV testing may not be available it is important to bear in mind that severe immunodepression and a clinical presentation compatible with AIDS do not necessary carry the diagnosis of AIDS.

Key words: Human immunodeficiency virus, Acquired immunodeficiency syndrome, Lymphopenia, Kaposi’s sarcoma, tuberculosis, Djibouti.

African Health Sciences 2012; 12(3): 331 - 333 http://dx.doi.org/10.4314/ahs.v12i3.13
\end{abstract}

\section{Case reports}

\section{Patient 1}

A 55-year-old male was admitted with a vesicular rash to the Hôpital Général Peltier in Djibouti. He was married with four children and all were in good health. The clinical history was non contributory and the physical examination revealed several vesicles filled with serous fluid distributed on the trunk and extremities; his weight was $52 \mathrm{~kg}$ (body mass index [BMI]: $18.4 \mathrm{~kg} / \mathrm{m}^{2}$ ). Blood analyses and a chest radiograph showed no abnormalities. A skin biopsy demonstrated bullous pemphygoid. The patient was started on oral steroids (30 $\mathrm{mg}$ prednisone/day) and was discharged when the vesicles dried up. He was seen twice as an outpatient with marked improvement and then was lost to follow-up after six months.

The patient returned one year later. Multiple bluish nodular lesions covered his eyelids, arms and trunk; he had not lost weight and the rest of the physical examination was normal. He was hospitalized. The hemoglobin was $8.7 \mathrm{~g} / \mathrm{dL}$ and the leukocyte count $12.7 \times 10^{3} / \mathrm{mm}^{3}$ with $6 \%$

\begin{tabular}{|l|}
\hline *Correspondence author: \\
Dr Jaime E. Ollé-Goig \\
Carretera de les Aigües \\
181. 08017 \\
Barcelona, Spain \\
Tel: 34932055576 \\
Email: olleuganda@gmail.com \\
\hline
\end{tabular}

African Health Sciences Vol 12 No 3 September 2012 lymphocytes, a CD4+ T cells count of $166 / \mu \mathrm{l}$ (BD FacScount Reagents, BD Biosociences, Becton, Dickinson and Co., San Jose, Ca, USA) and a CD4+ / CD8+ ratio of 0.8; ELISA test for HIV and viral load performed twice were all negative (Abbot Lab., Minato-Kuito, Tokyo, Japan and Immunocomb II HIV 1 and 2 Biospot. Orgenics Ltd., Courbevoie, France; Nuclisens, Nasba Diagnostics, Easy Q HIV1, BioMérieux, Marci L'Etoile, France); a chest radiograph demonstrated an enlarged mediastinum. After three days his family took him home and we learned that he had died a few days later. A skin biopsy obtained from the trunk showed a Kaposi's sarcoma. The immunohistochemical study for Kaposi sarcoma-associated herpes virus (HHV-8) was positive in the nuclei of neoplastic cells (NCLHHV8-LNA antibody, at 1/25 dilution; Novocastra lyophilized mouse monoclonal antibody human Herpesvirus type 8 [latent nuclear antigen], Leica Biosystems Newcastle Ltd. Newcastle Upon Tyne, United Kingdom).

\section{Patient 2}

A 30-year-old woman was admitted with shortness of breath; her weight was $38 \mathrm{~kg}$ (BMI: $14.8 \mathrm{~kg} / \mathrm{m}^{2}$ ). She had suffered from diarrhea and abdominal pain for the past four months and had no history of tuberculosis; she had been treated in a dispensary 
with antibiotics with no relief. Her husband had received treatment for tuberculosis (smear-positive sputum) during four months and was asymptomatic; her four children were in good health. Her weight was $28 \mathrm{~kg}$ and she was afebrile; her feet and ankles were edematous and no other abnormalities were noted. The hemoglobin was $10.4 \mathrm{~g} / \mathrm{dL}$ and the leukocyte count $5.2 \times 10^{3} / \mathrm{mm}^{3}$ with $9.2 \%$ lymphocytes, a low CD4+ count (28 CD $4+$ T cells/ $\mu \mathrm{l})$ and a CD4/CD8+ ratio of 0.9. Tests for HIV infection performed twice were all negative. A chest radiograph revealed bilateral upper lobe infiltrates with multiple cavities in the right upper lobe. The tuberculin test was not available and no sputum could be obtained; she was started on a four-drugs antituberculosis therapy. Her husband was HIV-negative and his chest radiograph was compatible with tuberculosis but was not able to produce any sputum. The patient died three days later.

\section{Discussion}

Idiopathic CD4+ lymphocytopenia has been reported in several areas of the World: Europe ${ }^{1-5}$, the Americas ${ }^{6-8}$, Australia ${ }^{9}$ and West Africa ${ }^{10-11}$ with AIDS-defining illnesses and in whom the etiology of the CD4+ T-lymphocyte depletion could not be explained. To our knowledge these cases are the first detected in East Africa. The presenting manifestations are varied: thrombocytopenia, opportunistic infections including tuberculosis and other mycobacterial infections, different types of malignancies, and autoimmune diseases ${ }^{12}$.

Our first patient was treated for pemphigus with steroids. He discontinued his treatment after several months and did not return until he had developed new lesions which turned out to be Kaposi's sarcoma. The development of Kaposi's sarcoma after treatment of pemphigus with steroids has already been described in a patient with idiopathic CD4+ lymphocytopenia ${ }^{13}$.

The second patient had radiological features suggesting pulmonary tuberculosis but the diagnosis could not be confirmed because on admission she was not coughing and she died shortly after. Her husband had been incompletely treated for tuberculosis and was also HIV-negative. Tuberculosis may reduce the lymphocyte subpopulations ${ }^{14}$, although this reduction usually does not reach the dramatic levels observed in our second patient. In Argentina, it was shown that patients with severe tuberculosis and with lower CD4 had a worse prognosis and that the CD4 lymphocytes increased to normal values after the response to treatment ${ }^{15}$. Our patient was severely malnourished and this is also a cause of immunodeficiency. A significant reduction of the CD4 lymphocytes can occur in conditions with no HIV infection ${ }^{16}$, including severe wasting, as described in Ethiopia ${ }^{17}$.

There is a close and complex relation between tuberculosis and malnutrition (18-20). Several studies suggest that as the BMI decreases, the incidence of tuberculosis increases (21-22) and that malnutrition maybe a predictor of poor outcome $\mathrm{e}^{23-24}$.

Idiopathic CD4 lymphocytopenia was defined in 1992 as a syndrome with $<300$ CD4+ T cells $/ \mu \mathrm{l}$ or $<20 \%$ of total $\mathrm{T}$ cells with no evidence of infection with HIV-1/HIV-2 and in the absence of any immunodeficiency or therapy associated with reduced levels of CD4 cells ${ }^{6}$. Studies have not observed an epidemiological pattern suggesting a new transmissible agent or an environmental factor ${ }^{7}$ contributing to its emergence. It constitutes a very rare syndrome which is probably caused by many factors. Its course seems to be more benign, as many patients do not suffer a progressive worsening of the lymphopenia and in some this reduction even disappears ${ }^{16}$. An explanation of this "new syndrome" could be that it already occurred in the past but that it was not recognized, as $T$ cell phenotyping was not widely applied until recent years.

In conclusion, the detection of a low CD4 does not always imply that the patient is infected with HIV, even when the patient suffers from an AIDS-defining entity and has no history of immunosuppressive therapy. Especially in limited resource areas where HIV testing is not always available such assumption could lead to an erroneous diagnosis of AIDS. We must bear in mind before diagnosing AIDS that the implications of this diagnosis for the patients and their families are severe.

\section{References}

1. Daus H, Schwarze G, Radtke H. Reduced CD4+ count, infections, and immune thrombocytopenia without HIV infection. Lancet 1989; 2:559-560.

2. Pankhurst C, Peakman M. Reduced CD4+ T cells and severe oral candidiasis in absence of HIV infection. Lancet 1989; 1:672.

3. Jowitt SN, Love EM, Liu Yin JA. CD4 lymphocytopenia without HIV in a patient with cryptococcal infection. Lancet 1991; 337:500-501. 
4. Cozon G, Greenland T, Revillard JP. Profound CD4+ lymphocytopenia in the absence of HIV infection in a patient with visceral leishmaniasis. N Eng J Med 1990; 322:132.

5. Castro A, Pedreira J, Soriano V, Hewlet I, Jhosi B, Epstein J et al. Kaposi's sarcoma and disseminated tuberculosis in HIV-negative individual. Lancet 1992; 339:868.

6. Unexplained CD4 T-lymphocyte depletion in persons without evident HIV infection - United States. MMWR 1992; 41:541-545.

7. Smith DK, Neal JJ, Holmberg SD, and the Centers for Disease Control Idiopathic CD4+ Tlymphocytopenia Task Force. Unexplained opportunistic infections and $\mathrm{CD} 4+\mathrm{T}$ lymphopenia without HIV infection. $N$ Eng J Med 1993; 328:373-379.

8. Ho DD, Cao Y, Zhu T, Farthing C, Wang N, Gu $\mathrm{G}$ et al. Idiopathic CD4+ T-lymphocytopenia Immunodeficiency without evidence of HIV infection. N Eng J Med 1993; 328:380-385.

9. Gatenby PA. Reduced CD4+ T cells and candidiasis in absence of HIV infection. Lancet 1989; 1:1027-1028.

10. Djomand G, Diaby L, N'Gbichi J-M, Coulibaly D, Kadio A, Yapi A et al. Idiopathic CD4+ Tlymphocyte depletion in a West African population. AIDS 1994; 8:843-847.

11. Kony SJ, Hane AA, Larouzé B, Samb A, Cissoko $\mathrm{S}$, Sow PS et al. Tuberculosis-associated severe CD4+ T-lymphopenia in HIV-seronegative patients from Dakar. J Infection 2000; 41:167171.

12. Walker U, Warnatz K. Idiopathic lymphopenia. Current Opinion in Rheumatology 2006. 18:389-395.

13. Fierro MT, Savoia P, Quaglino P, Novero D, Bernengo MG. Disseminated Kaposi's sarcoma associated with idiopathic CD4+ lymphocytopenia and low dose steroid therapy. Clin Exp Dermatol 2005; 30:395-397.

14. Jones BE, Oo MM, Talkwel EK, Qian D, Kumar A, Maslow ER et al. CD4 cell counts in human immunodeficiency virus-negative patients with tuberculosis. Clin Infect Dis 1997; 24:988-991.
15. Pilheu JA, De Salvo MC, Gonzalez J, Rey D, Elias MC, Ruppi MC. CD4+ T-lymphopenia in severe pulmonary tuberculosis without evidence of human immunodeficiency virus infection. Int J Tuberc Lung Dis 1997; 1:422-426.

16. Duncan RA, von Reyn F, Alliegro GM, Toossi Z, Sugar AM, Levitz SM. Idiopathic CD4+ Tlymphocytopenia - Four patients with opportunistic infections and no evidence of HIV infection. N Eng J Med 1993; 328:393-398.

17. Abuye C, Tsegaye A, West CE, Versloot P, Sanders EJ, Wolday D et al. Determinants of CD4 counts among HIV-negative Ethiopians: role of body mass index, gender, cigarette smoking, khat (Catha edulis) chewing, and possibly altitude? J Clin Immunol 2005; 25:127-133.

18. Kennedy N, Ramsay A, Uiso L, Gutmann J, Ngowi FI, Gillespie SH. Nutritional status and weight gain in patients with pulmonary tuberculosis in Tanzania. Trans $\mathrm{R}$ Soc Trop Med Hyg 1996; 90:162-166.

19. Metcalfe N. A study of tuberculosis, malnutrition and gender in Sri Lanka. Trans $\mathrm{R}$ Soc Trop Med Hyg 2005; 99:115-119.

20. Harries AD, Nkhoma WA, Thompson PJ, Nyangulu DS, Wirima JJ. Nutritional status in Malawian patients with pulmonary tuberculosis and response to chemotherapy. Eur J Clin Nutr 1988; 42:445-450.

21. Lonnröth K, Williams BG, Cegielski P, Dye C. A consistent log-linear relationship between tuberculosis incidence and body mass index. Inter J Epidemiol 2010; 39:149-155.

22 Cegielski JP, McMurray DN. The relationship between malnutrition and tuberculosis: evidence from studies in humans and experimental animals. Int J Tuberc Lung Dis 2004; 8:286-298.

23. Byrd Jr., RP. Malnutrition and pulmonary tuberculosis. Clin Infect D 2002; 35:634-635.

24. Zachariah R, Spielmann MP, Harries AD, Salaniponi FML. Moderate to severe malnutrition in patients with tuberculosis is a risk factor associated with early death. Trans $\mathrm{R}$ Soc Trop Med Hyg 2002; 96:291-294. 